\title{
Review Article \\ Ethical, Socioeconomic, and Cultural Considerations in Gynecologic Cancer Care in Developing Countries
}

\author{
Uzochukwu Uzoma Aniebue $^{1}$ and Tonia Chinyelu Onyeka ${ }^{2}$ \\ ${ }^{1}$ Department of Obstetrics and Gynecology/Gynae-Oncology Unit, Multidisciplinary Oncology Center, \\ University of Nigeria Teaching Hospital, Ituku-Ozalla, Enugu PMB 01129, Nigeria \\ ${ }^{2}$ Department of Anaesthesia/Pain and Palliative Care Unit, Multidisciplinary Oncology Center, University of Nigeria Teaching Hospital, \\ Ituku-Ozalla, Enugu PMB 01129, Nigeria
}

Correspondence should be addressed to Tonia Chinyelu Onyeka; doctortoniaonyeka@gmail.com

Received 22 April 2013; Accepted 11 November 2013; Published 19 January 2014

Academic Editors: D. Heigener, C. Knapp, and R. Viola

Copyright (C) 2014 U. U. Aniebue and T. C. Onyeka. This is an open access article distributed under the Creative Commons Attribution License, which permits unrestricted use, distribution, and reproduction in any medium, provided the original work is properly cited.

\begin{abstract}
Gynaecologic cancers contribute significantly to the cancer burden in developing countries, resulting in higher mortality and morbidity rates among women in these nations. This situation is further compounded by the occurrence of wars, famine, poverty and natural disasters, and infectious diseases like hepatitis B and HIV/AIDS. In addition, merge resources and manpower lack in these countries further compound this very delicate situation. Often times, socioeconomic, cultural, and ethical factors such as truth-telling, choice of place of care, place of death, treatment choices, medication use, and terminal sedation can interfere in patient management. Availability and use of oral morphine for pain relief, spiritual care and availability of palliative care services, the individuals' autonomy, and family and community participation in care, end of life issues, and preservation of fertility are also big issues that determine the course of care. This review discusses these pertinent factors, discusses how they affect cancer care in women, and proffers ideas for healthcare workers and policy makers on implementation of sustainable models for cancer care in developing countries. Addressing socioeconomic, cultural, and ethical issues affecting gynaecologic cancer care will aid in ensuring development of viable models of cancer care in resource-limited countries.
\end{abstract}

\section{Introduction}

Chronic medical diseases and cancers are becoming emerging diseases of public health importance in developing countries. The burden of gynaecologic cancers is on the increase worldwide but is disproportionately higher in developing than developed countries, with the former accounting for about five million new cancer diagnoses annually [1]. This situation, worsened by wars, poverty, and natural disasters, is mainly due to socioeconomic and cultural factors that lead to late diagnosis, high drop-out rates from treatment, high mortality, and poor followup of cancer survivors [2-4]. While the majority of these countries have efforts to combat the scourge of gynaecologic disease hampered by lack of resources (drugs and finances) and medical manpower, they are known to have rich and diverse cultures where religions, traditions, and family values greatly influence medical decisions.

Cervical cancer is the second most common cancer in women worldwide. In Sub-Saharan Africa, nearly $70 \%$ of women afflicted with the condition live in rural areas, in poverty, and lack access to basic amenities like water and health care infrastructure [5]. In addition, large majorities are at the prime of reproductive life when demand of motherhood and socioeconomic responsibilities in the family places an enormous burden on them. Delays in diagnosis and poor healthcare seeking behaviour are common with these patients. Ovarian cancers are leading causes of mortality from cancer in women worldwide [6]. Late diagnoses and the required long, complex, and often very aggressive and costly treatment make the management of ovarian cancers 
in developing countries very challenging. Vulval cancer, endometrial cancer, and primary cancers of vagina and fallopian tubes are much less common but poise similar problems with the more common gynaecologic cancers. Patients with advanced forms of these cancers have need of palliative care which improves quality of life by elimination or reduction of pain and other distressing symptoms of the disease. The World Health Organization (WHO) has named palliative care as one of four strategies to cancer control, with other three being cancer prevention, early detection and diagnosis, and treatment [7]. The management of these patients is often fraught with socioeconomic, cultural, and ethical dilemmas. These have been noted to include truthtelling, choice of place of care and place of death, treatment choices, medication use, and terminal sedation [8]. Availability and use of oral morphine for pain relief, spiritual care, and availability of palliative care services have been cited as issues [8]. Other common ethical challenges include issues of the individuals' autonomy, family and community participation in care, end-of-life issues, and preservation of fertility. For successful development of a viable and sustainable model of cancer care in resource-poor environments, all these issues must be dealt with.

\section{Culture and Religion}

Culture is defined as "the forms of traditional behaviour which are characteristic of a given society or of a group of societies, or of a certain race, or of certain area, or of a certain period of time" [9]. Diversity of cultural and religious beliefs of people in the developing world, especially Africa, the Middle East, and Asia, affects their views and perceptions of cancer care. Therefore, if healthcare in these regions are to be improved upon, then the cultures, traditions, and religious inclinations of patients with origins from there should be taken into consideration. Many African and Middle Eastern countries consider mentioning cancer a taboo and many forbid the telling of a patient that he/she is dying [10, 11]. In South Africa, cultural and gender norms precludes women discussing sexuality issues with their daughters [12]. In Bangladesh, women have little access to healthcare facilities, a situation compounded by the notion that they are not to take decisions concerning their health by themselves [13]. In the predominantly matriarchal Serbian society, hysterectomy is dreaded and often rejected as a woman's position in family is assured by birth of a child, especially male child [14, 15]. Because of strong support arrangement provided by extended family system in African and similar cultures, there seems to be reduced relevance for psychologists, social workers, and psychiatrists in cancer care [16] and this system has once been noted to provide emotional stability to cancer patients in Kenya [1].

\section{Socioeconomic Issues}

Poverty has very serious implications for women with gynaecologic cancer in the developing world. Appropriate therapeutic interventions like radiotherapy are not only sparsely available in these countries but their use is limited by high costs and dearth of experienced manpower. The increasing disease burden and large country populations overwhelms the public health system, putting a strain on limited finite resources [17]. In a study by Murray et al. [18], many Kenyan cancer patients hid their diagnosis from family members because of the financial burdens of hospital and medication payments. In about $90 \%$ of cases, cervical cancer is linked to persistent genital infection with oncogenic strains of human papilloma virus (HPV). Lack of knowledge about the cervical cancer, HPV, and regular screening and meager finances contribute in no small measure to the disease burden.

HPV infection is most common in young women within their first decade of sexual activity [19] and new vaccine has been developed for prevention following exposure to high-risk HPV [19]. However, several societies are fearful and wary of the vaccines, believing they are government's effort at controlling fertility [20]. Male infidelity as well as early marriages/child marriages are accepted norms in many of these cultures [21] that promote the infection, a situation worsened by near nonexistent of both populationbased screening of cervical cancers and availability of human papilloma virus vaccines as well as its high cost $[22,23]$.

\section{Health Inequity}

With cervical cancer, cytological screening enables detection of precursor lesion long before onset of invasive disease. Advances in cytological examination use liquidbased cytology and show superior performance to conventional methods in population-based cervical cancer screening programs [24]. Colposcopic services where available have made early diagnosis and treatment of preinvasive disease output procedures. These standard treatment options are often absent or unaffordable in most low resource countries creating ethical dilemma in societies with high disease burden. In addition, compliance to these "hightech" treatments is further reduced due to their unpleasantness and protracted duration of administration. Fertilitysparing procedures like radical trachelectomy performed in women of child-bearing age with early stage cervical cancer in developed countries [25] is largely unavailable in the developing world due to high treatment costs, equipment and expertise lack, late disease presentation, and religious taboos.

Ovarian cancers have the highest mortality among gynaecologic cancers even in developed countries [6]. The use of specialized treatment centres and government guaranteed fast tracking of treatment which was made free for all cancers in a developed country like Denmark resulted in remarkably improved outcome [3]. However, individual cost bearing remains the main stay of financing for cancer care in most developing countries. Consequently cancer care services remain grossly underfunded and many patients dropout. Also, research in gynaecologic oncology suffers from poor funding in developing countries and is compounded by poor record keeping and follow-up attendance. 


\section{Ethical Issues}

Medical ethics is an important part of the practice of every physician and this is particularly true in oncology. It has been defined as disciplined study of morality in medicine which concerns obligations of physicians and health-care organizations to patients as well as obligation of patients [26]. Gynaecologic oncologist must learn to recognize ethical issues peculiar to their practice environment and ensure their resolution as part of total care of the gynaecologic cancer patient. These issues include the right to know, end of life decisions, death and dying, and health inequities.

\section{The Right to Know}

Issues related to management of information in patient receiving treatment for cancer is at the centre of literature on communication in cancer. Questions of "when," "how," and "how much" to disclose and "to whom disclosure is to be made" remain contentious in the care of cancer patients [27]. Informing patients with cancer the truth about their diagnosis and progress or otherwise was until recently presumed harmful to patient [28]. The paternalistic concept in communication in which the physician was trusted to act independently in the best interest of patient was widely practiced [29]. With increasing adoption of informed consent as gold standard of care, patients were required to act autonomously with regard to authorization of medical procedures and treatment. This made full disclosure of information by physicians obligatory. Despite this trend in care of cancer patients, need for information seems to vary between patients and across cultures [30]. Physicians in restrictive cultures such as Africa and some Asian countries remain unsupportive of fully disclosure of information to patients particularly of "bad news" [31, 32]. This is in contrast to attitude of physicians in more open West European countries with high regard for patient's autonomy. In most African, Hispanic, and Asian cultures, the nuclear family is very strong and sentiments among family members influence patient's choices and decisions [33]. Surrogate decision makers may however arguably be an expression of patient's autonomy provided such persons are freely delegated to function by the patient. Even in the absence of cultural restrictions some patients prefer avoidance of bad news and delegate decision making to family members $[34,35]$. Sentiment of family members occasionally creates ethical problems by beclouding honest and sincere discussion of patients' progress. It is not uncommon to be clearly instructed by the family not to discuss with or disclose certain information to patient. Patient's religious conviction, educational attainment, age, and psychological maturity tend to influence this attribute. This emphasizes the need for adoption of standard effective and validated ways of breaking bad news such as the SPIKES protocol [36].

\section{End of Life Decisions}

The final stage in life cycle of man is dying. Provision of humane care to patients when curative remedies and therapies are no longer feasible or palliative care is an essential part of caring for cancer patients. Palliative care goes beyond hospice or comfort care to encompass meeting the physical, mental, and spiritual needs of patients and their families [37]. It involves early identification and treatment of pain and any other physical, psychological, and spiritual problems associated with the progression of illness [38]. Dying is regarded in palliative care as a natural process which is neither to be hastened nor unduly prolonged while maintaining the patient as active as possible until death. The aim is a dignified death free of pain. The current concept of palliative care is that it should be instituted in care of those with life threatening illness long before it becomes terminal. Palliative care is instituted alongside curative treatment to enhance quality of life at every stage of treatment.

Ethical problems abound in palliative care particularly in conflicts resulting from assertion of individual rights and preferences at end of life. An area of frequent conflict is insistence of patient or family on use of particular treatments or remedy with unproven effectiveness. A survey of cancer patients in the United States of America (USA) showed that one in every three respondents had used at least one unconventional therapy in the past year [39, 40]. Similarly, physicians' response to patients who are noncompliant to appointments, prescriptions, and recommended medical care can be very ethically challenging. Exploration of situational clues may help elucidate their challenges in compliance and enhance better understanding of the "difficult patient." This helps in development of a more flexible and suitable care for such patients.

The definition of appropriate care becomes more complex as illness progresses and becomes terminal. Ethical questions arise as to when to withhold standard curative treatment and switch to hospice. The essence of repeated surgeries and chemotherapy becomes disputable and questions arise like "Should treatment be solely directed at alleviating symptoms?", "When should resuscitation be withheld?" and "Is there any place for physician assisted death or euthanasia?"

Terminally ill patients tend to have varying degrees of depression which may find expression in suicidal tendencies due to feeling that life has become useless. Assisted death is then requested for despite patients' fear of death. Advocates of euthanasia relate it to patients' right of autonomy in end of life decisions. Physician assisted suicide (PAS) became legal in Oregon and Washington of the USA in 1997 and 1999, respectively, while Belgium (2002), the Netherlands (2002), and Luxemburg (2008) have legalized both PAS and euthanasia [41, 42]. Request for euthanasia was found most common in patients with motor disorders, cognitive disorders, feeding difficulty, loss of communication ability, sense of loss of dignity, and elimination disorder [43]. The reality and magnitude of euthanasia and its demand is largely unknown in most developing countries due to societal repression of such discussion. In most African and Asian cultures with restrictive cultural inclination to issues of death and dying, open and direct end of life discussion is often considered very offensive [44, 45]. Active euthanasia is criminalized and the religious among its society continue to oppose it by proclaiming the sacredness of life which can only be taken by the one who created it [46]. 


\section{Death and Dying}

Societal attitude to death and dying is another important barrier to free communication with women suffering from cancer. They are multidimensional and vary across cultures. In most west European countries, disease, death, and dying are regarded more naturally than in African and Asian cultures. Family dynamics and religion play major roles in shaping the African and Asian concepts of death. The young adult is permitted early in life to practice nonnuclear family life independence in West European culture. In African and Asian cultures, individuals exist within a nuclear family based on marriage and creating a very strong family-based bond and are adversely affected by demise of other family members. Family members have been known to be the leading source of complimentary therapies in patients with cancer [47]. Acting as surrogate decision makers, they occasionally insist on futile medical treatments that may not change the overall outcome of patients. Death and dying is a deeply emotional event in most African and Asian cultures. These emotions similarly stir positive family reactions which represent a unique resource in patient care and impacts very positively on care of people with cancer $[48,49]$. A wide range of studies suggest that $50-75 \%$ terminally ill patients, including those with cancer, prefer home-based care [38].

Families need to be educated appropriately and prepared on time for financial implications and emotional pressures associated with caring for the terminally ill and their subsequent demise. The challenges which result in unsupportive and emotionally devastated families of cancer patients have largely been underestimated and seldom studied in the developing world [50]. It would be interesting to determine the factors which militate against effective family support in treatment of such patients with a view to developing a scale for measuring family support indexes in care of women with gynaecologic cancers. Religion has dramatically different connotations in various cultures with prime drivers as history, politics, social events, and theological arguments [51]. Religiosity tends to bear a great deal on each cultures' concept of death and dying. In association with personal attributes, religion plays a vital role in determining patients' response to truth about their condition [52]. Religious, emotional, and psychological support ameliorate impact of bad news and help patients adjust to reality of their situation [53].

\section{Conclusion}

Provision of financially sustainable models of cancer care remains the challenge in the treatment of cancer worldwide but particularly in low resource countries. Addressing socioeconomic, cultural, and ethical issues affecting gynaecologic cancer care will aid in ensuring development of viable models of cancer care in resource-limited countries. Unrestrained and uncritical adoption of new technologies without commensurating cost benefit analyses remains the rule in the technology deprived and gullible communities where any form of technology is rapturous once found. It is important that policy makers on healthcare in developing countries emphasize the optimal use of scarce resources based on evidence-based practices.

Health education and population-based screening is cheaper and more effective in the management of most gynaecologic cancers. Health education should be institutionalized using mass media and other culturally acceptable means of community mobilization. Systematic, available, and affordable cancer screening should be incorporated into basic health care. Healthcare practitioners need to accept limited life expectancy in patients with advanced cancers. They should know when and be readily willing to switch to palliative care where necessary. A strong collaboration between gynaecologists, palliative care physicians, and general surgeons is essential for optimal gynaecologic cancer care. In addition, research in developed countries should emphasize feasibility treatment plans, provision of affordable chemotherapeutic drugs, surveillance of cancer survivors, family therapy, and the vital role of counsellors and social welfare practitioners in the care of cancer.

\section{Conflict of Interests}

The authors declare that there is no conflict of interests regarding the publication of this paper.

\section{References}

[1] K. Crane, "Cancer in the developing world: palliative care gains ground in developing countries," Journal of the National Cancer Institute, vol. 102, no. 21, pp. 1613-1615, 2010.

[2] B. Slusarska, D. Zarzycka, M. Wysokiński, A. Sadurska, I. Adamska-Kuźmicka, and M. Czekirda, "Health behaviours and cancer prevention among Polish women," European Journal of Cancer Care, vol. 19, no. 6, pp. 786-794, 2010.

[3] L. Seibaek, L. K. Petersen, J. Blaakaer, and L. Hounsgaard, "Hoping for the best, preparing for the worst: the lived experiences of women undergoing ovarian cancer surgery," European Journal of Cancer Care, vol. 21, no. 3, pp. 360-371, 2012.

[4] M. Schiffman, P. E. Castle, J. Jeronimo, A. C. Rodriguez, and S. Wacholder, "Human papillomavirus and cervical cancer," The Lancet, vol. 370, no. 9590, pp. 890-907, 2007.

[5] A. Ntekim, "Cervical cancer in sub sahara africa," in Topics on Cervical CAncer with an Advocacy for Prevention, R. Rajamanickam, Ed., InTech, 2012.

[6] M. P. Coleman, D. Forman, H. Bryant et al., "Cancer survival in Australia, Canada, Denmark, Norway, Sweden, and the UK, 1995-2007 (the international cancer benchmarking partnership): an analysis of population-based cancer registry data," The Lancet, vol. 377, no. 9760, pp. 127-138, 2011.

[7] World Health Organization, National Cancer Control Programmes: Policies and Managerial Guidelines, 2002.

[8] T.-Y. Chiu, W.-Y. Hu, S.-Y. Cheng, and C.-Y. Chen, "Ethical dilemmas in palliative care: a study in Taiwan," Journal of Medical Ethics, vol. 26, no. 5, pp. 353-357, 2000.

[9] C. Brumann, L. Abu-Lughod, E. L. Cerroni-Long et al., "Writing for culture: why a successful concept should not be discarded [and comments and reply]," Current Anthropology, vol. 40, pp. S1-S27, 1999. 
[10] Stratis Health, "Culture care connection: asian Indians in Minnesota," http://www.culturecareconnection.org/matters/diversity/asianindian.html.

[11] Stratis Health, "Culture care connection: Somalis in Minnesota," http://www.culturecareconnection.org/matters/diversity/ somali.html.

[12] S. A. Francis, M. Battle-Fisher, J. Liverpool et al., "A qualitative analysis of South African women's knowledge, attitudes, and beliefs about HPV and cervical cancer prevention, vaccine awareness and acceptance, and maternal-child communication about sexual health," Vaccine, vol. 29, no. 47, pp. 8760-8765, 2011.

[13] E. R. Winstead, "In Bangladesh, developing models for cancer care," http://www.cancer.gov/ncicancerbulletin/113010/page3.

[14] M. Blagojevic, "Motherhood in Serbia: self-sacrificing paradox," Sociologija, vol. 34, no. 4, pp. 625-648, 1996.

[15] M. Sukovic, Hysterectomies and gender identity among serbian women [M.S. thesis], College Station, Texas A \& M University, 2007.

[16] E. Ben-Ari, "Considering Culture when Providing Cancer Care," http://www.cancer.gov/ncicancerbulletin/113010/page6.

[17] R. Harding, "Palliative care in resource-poor settings: fallacies and misapprehensions," Journal of Pain and Symptom Management, vol. 36, no. 5, pp. 515-517, 2008.

[18] S. A. Murray, E. Grant, A. Grant, and M. Kendall, "Dying from cancer in developed and developing countries: lessons from two qualitative interview studies of patients and their carers," British Medical Journal, vol. 326, no. 7385, pp. 368-371, 2003.

[19] T. C. Wright, "Natural history of HPV infections," The Journal of Family Practice, vol. 58, no. 9, pp. 53-57, 2009.

[20] J. M. Agosti and S. J. Goldie, "Introducing HPV vaccine in developing countries-key challenges and issues," The New England Journal of Medicine, vol. 356, no. 19, pp. 1908-1910, 2007.

[21] United Nations Children's Fund (UNICEF), Early Marriage: a Harmful Traditional Practice, a Statistical Exploration, UNICEF, New York, NY, USA, 1st edition, 2005.

[22] P. Basu and D. Chowdhury, "Cervical cancer screening \& HPV vaccination: a comprehensive approach to cervical cancer control," Indian Journal of Medical Research, vol. 130, no. 3, pp. 241-246, 2009.

[23] S. Goldie, "CHAPTER 10 A public health approach to cervical cancer control: considerations of screening and vaccination strategies," International Journal of Gynecology and Obstetrics, vol. 94, no. 1, pp. S95-S105, 2006.

[24] H. Beerman, E. B. L. van Dorst, V. Kuenen-Boumeester, and P. C. W. Hogendoorn, "Superior performance of liquid-based versus conventional cytology in a population-based cervical cancer screening program," Gynecologic Oncology, vol. 112, no. 3, pp. 572-576, 2009.

[25] C. A. F. Riberio, C. J. I. Ferreira, M. F. Costa, and A. P. Branco, "Fertility-sparing surgery for early-stage cervical cancer," International Journal of Surgical Oncology, vol. 2012, Article ID 936534, 11 pages, 2012.

[26] F. A. Chervenak and L. B. McCullough, "Ethics in obstetrics and gynecology: an overview," European Journal of Obstetrics \& Gynecology and Reproductive Biology, vol. 75, pp. 91-94, 1997.

[27] D. Oken, "What to tell cancer patients. A study of medical attitudes," The Journal of the American Medical Association, vol. 175, pp. 1120-1128, 1961.

[28] Y. Beyene, "Medical disclosure and refugees_telling bad news to Ethiopian patients," Western Journal of Medicine, vol. 157, no. 3, pp. 328-332, 1992.
[29] L. Grassi, T. Giraldi, E. G. Messina, K. Magnani, E. Valle, and G. Cartei, "Physicians' attitudes to and problems with truth-telling to cancer patients," Supportive Care in Cancer, vol. 8, no. 1, pp. 40-45, 2000.

[30] J. Mossman, M. Boudioni, and M. L. Slevin, "Cancer information: a cost-effective intervention," European Journal of Cancer, vol. 35, no. 11, pp. 1587-1591, 1999.

[31] C. Sepulveda, V. Habiyambere, J. Amandua et al., "Quality care at the end of life in Africa," British Medical Journal, vol. 327, no. 7408, pp. 209-213, 2003.

[32] K. C. Nwankwo and E. Ezeome, "The perceptions of physicians in Southeast Nigeria on truth-telling for cancer diagnosis and prognosis," Journal of Palliative Medicine, vol. 14, no. 6, pp. 700703, 2011.

[33] M. P. Schlumbrecht, C. M. Gallagher, C. C. Sun, L. M. Ramondetta, and D. C. Bodurka, "Ethics consultation on a gynecologic oncology service: an opportunity for physician education," Journal of Cancer Education, vol. 26, no. 1, pp. 183-187, 2011.

[34] M. Fujimori and Y. Uchitomi, "Preferences of cancer patients regarding communication of bad news: a systematic literature review," Japanese Journal of Clinical Oncology, vol. 39, no. 4, pp. 201-216, 2009.

[35] S. T. Tang and S.-Y. C. Lee, "Cancer diagnosis and prognosis in Taiwan: patient preferences versus experiences," PsychoOncology, vol. 13, no. 1, pp. 1-13, 2004.

[36] W. F. Baile, R. Buckman, R. Lenzi, G. Glober, E. A. Beale, and A. P. Kudelka, "SPIKES: a six-step protocol for delivering bad news: application to the patient with cancer," Oncologist, vol. 5, no. 4, pp. 302-311, 2000.

[37] S. J. Nass and E. Balogh, "National cancer policy summit: addressing opportunities and challenges in cancer care and research," Clinical Pharmacology and Therapeutics, vol. 89, no. 6, pp. 770-771, 2011.

[38] E. Davis and I. J. Higginson, "Rights and options," in Solid Facts: Palliative Care, E. Davis and I. J. Higginson, Eds., pp. 16-17, World Health Organisation (WHO), Copenhagan, Denmark, 1st edition, 2004.

[39] D. M. Eisenberg, R. C. Kessler, C. Foster, F. E. Norlock, D. R. Calkins, and T. L. Delbanco, "Unconventional medicine in the United States-Prevalence, costs, and patterns of use," The New England Journal of Medicine, vol. 328, no. 4, pp. 246-252, 1993.

[40] E. Ernst and B. R. Cassileth, "The prevalence of complementary/alternative medicine in cancer: a systematic review," Cancer, vol. 83, pp. 777-782, 1998.

[41] J. Pereira, "Legalizing euthanasia or assisted suicide: the illusion of safeguards and controls," Current Oncology, vol. 18, no. 2, pp. e38-e48, 2011.

[42] F. S. Oduncu and S. Sahm, "Doctor-cared dying instead of physician-assisted suicide: a perspective from Germany," Medicine, Health Care and Philosophy, vol. 13, no. 4, pp. 371-381, 2010.

[43] E. Ferranda, J. Dreyfusa, M. Chastrussea, F. Ellienb, F. Lemairec, and M. Fischlera, "Evolution of requests to hasten death among patients managed by palliative care teams in France: a multicenter cross-sectional survey (Demand E)," European Journal of Cancer, vol. 48, pp. 368-376, 2012.

[44] J. A. Carrese and L. A. Rhodes, "Western bioethics on the Navajo reservation: benefit or harm?" Journal of the American Medical Association, vol. 274, no. 10, pp. 826-829, 1995.

[45] M.-C. S. Pang, "Protective truthfulness: the Chinese way of safeguarding patients in informed treatment decisions," Journal of Medical Ethics, vol. 25, no. 3, pp. 247-253, 1999. 
[46] A. O. Nwafor, "Comparative perspectives on euthanasia in Nigeria and Ethiopia," African Journal of International and Comparative Law, vol. 18, pp. 170-191, 2009.

[47] E. R. Ezeome and A. N. Anarado, "Use of complementary and alternative medicine by cancer patients at the University of Nigeria Teaching Hospital, Enugu, Nigeria," BMC Complementary and Alternative Medicine, vol. 7, article 28, 2007.

[48] B. Ferrell, K. Ervin, S. Smith, T. Marek, and C. Melancon, "Family perspectives of ovarian cancer," Cancer Practice, vol. 10, no. 6, pp. 269-276, 2002.

[49] D. Koldjeski, M. K. Kirkpatrick, L. Everett, S. Brown, and M. Swanson, "The ovarian cancer journey of families the first postdiagnostic year," Cancer Nursing, vol. 30, no. 3, pp. 232-242, 2007.

[50] T. R. Norton, S. L. Manne, S. Rubin et al., "Ovarian cancer patients' psychological distress: the role of physical impairment, perceived unsupportive family and friend behaviors, perceived control, and self-esteem," Health Psychology, vol. 24, no. 2, pp. 143-152, 2005.

[51] P. Beyer, "Social forms of religion and religions in contemporary global society," in Handbook of the Sociology of Religion, M. Dollon, Ed., pp. 45-60, Cambridge University Press, Cambridge, UK, 1st edition, 2003.

[52] C. De Pentheny O'Kelly, C. Urch, and E. A. Brown, "The impact of culture and religion on truth telling at the end of life," Nephrology Dialysis Transplantation, vol. 26, no. 12, pp. 38383842, 2011.

[53] K. Mystakidou, E. Tsilika, E. Parpa, E. Katsouda, and L. Vlahos, "Patterns and barriers in information disclosure between health care professionals and relatives with cancer patients in Greek society," European Journal of Cancer Care, vol. 14, no. 2, pp. 175181, 2005. 


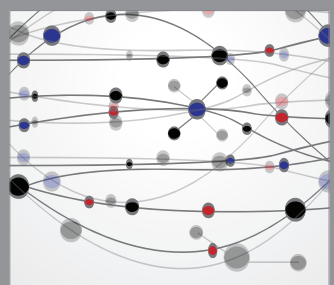

The Scientific World Journal
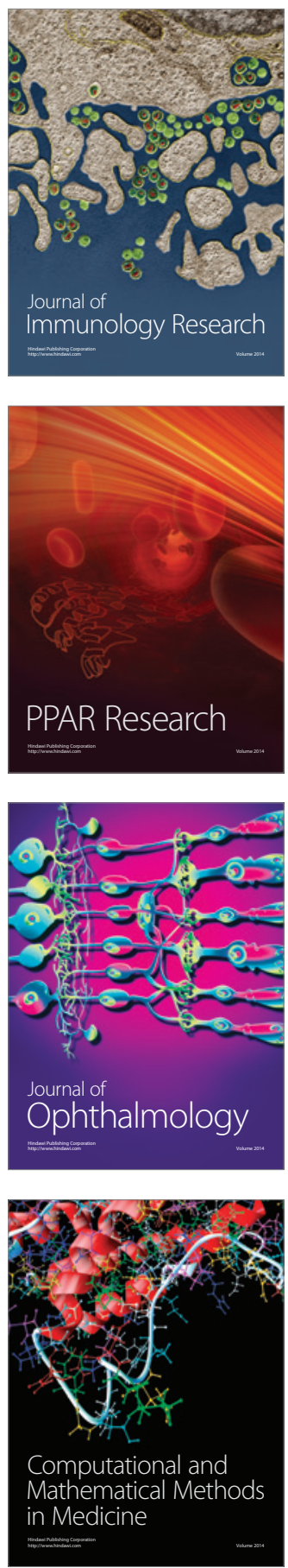

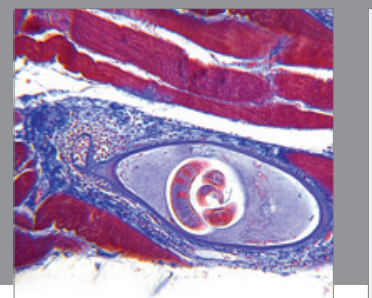

Gastroenterology

Research and Practice
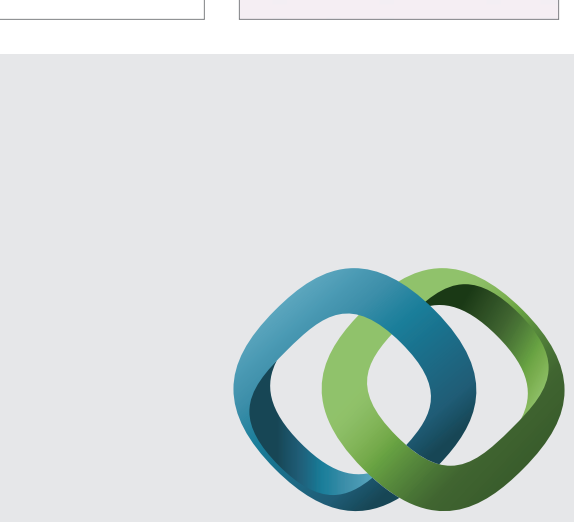

\section{Hindawi}

Submit your manuscripts at

http://www.hindawi.com
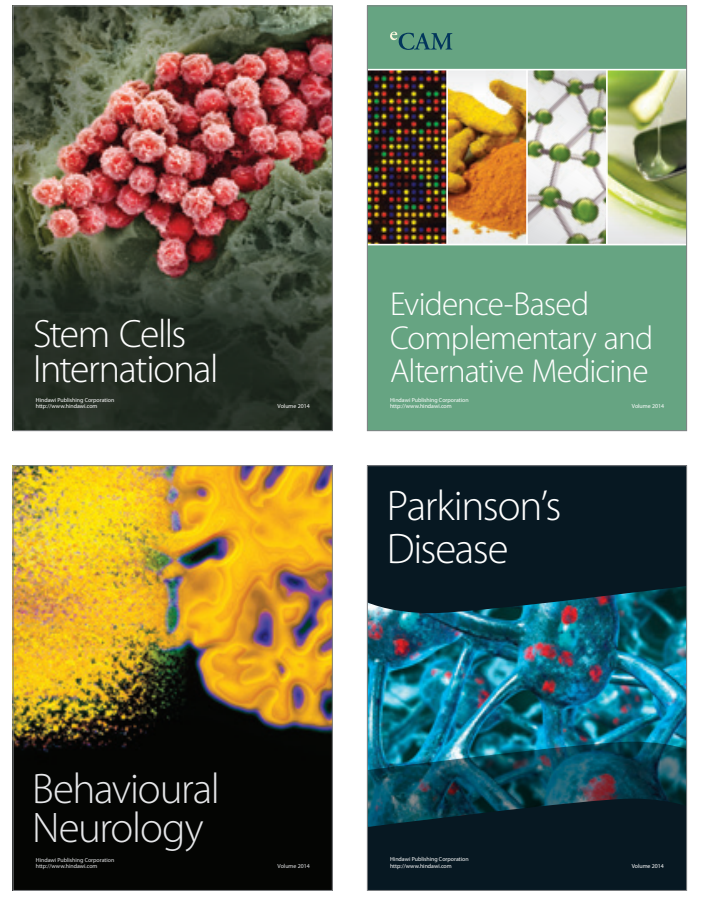
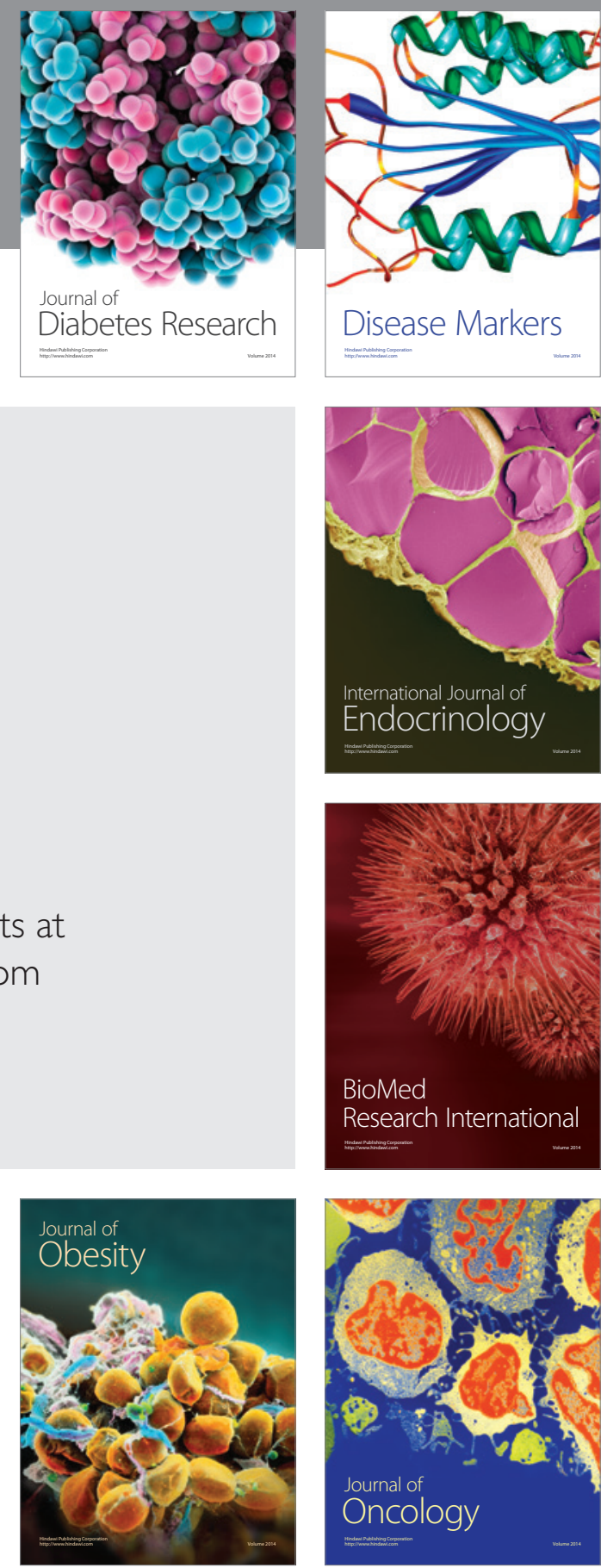

Disease Markers
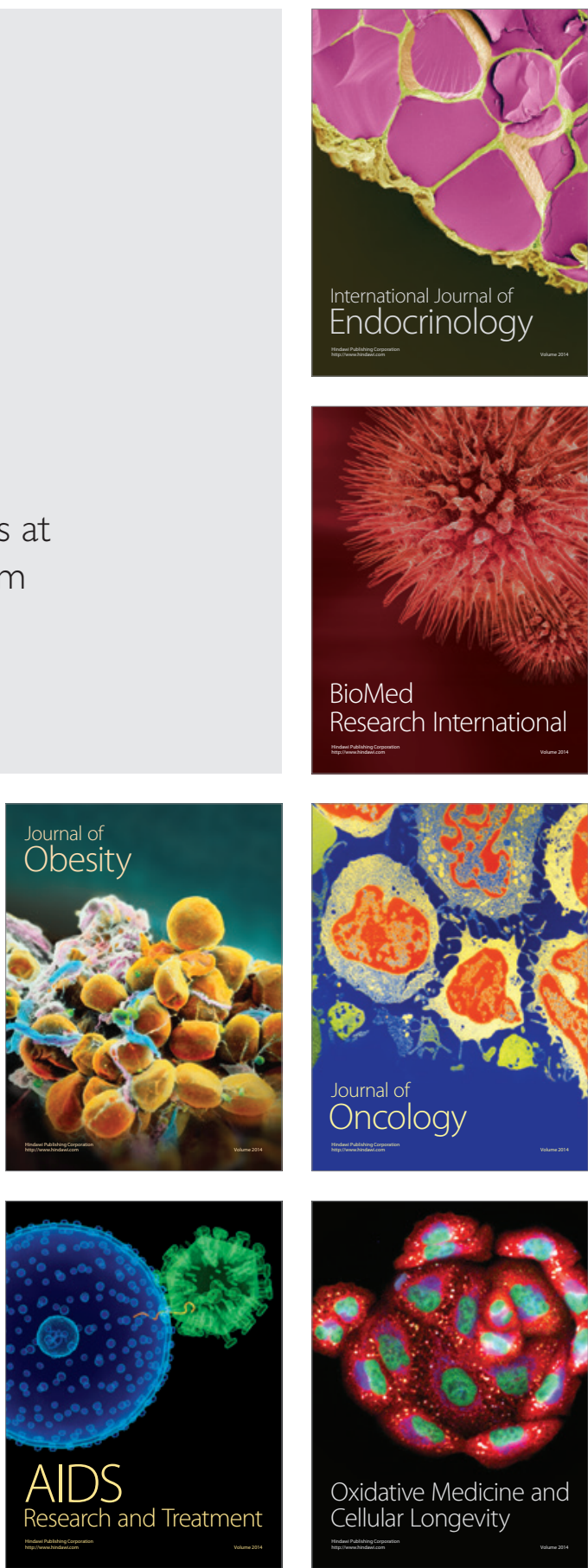